\title{
Satisfaction Among International Student-Athletes Who Participate in the National Collegiate Athletic Association
}

\author{
Sylvia Trendafilova, Robin Hardin, and Seungmo Kim \\ University of Tennessee
}

\begin{abstract}
The number of international student-athletes participating in the National Collegiate Athletic Association (NCAA) has nearly doubled from 8,945 in 2001-02 to 16,440 in 2007-08 (DeHass, 2009). As a result of such dramatic growth in the number of student-athletes participating in NCAA athletics, it is important to understand the level of satisfaction among this group. Determining whether athletes are satisfied with their experience may aid in recruiting future international athletes as well as potentially leading to higher retention and graduation rates. Thus, the purpose of this study was to explore the level of satisfaction (academic and athletic) among international student-athletes who participate in NCAA Division I-Football Bowl Subdivision athletics. Data analysis revealed that international student-athletes are satisfied with the dimensions measuring satisfaction, including academic support services, personal treatment, team social contribution and medical support. In addition, male athletes are more satisfied with external agents (i.e., media, the local and university community) than female athletes. These findings will not only help coaches and administrators better understand international student-athletes' academic and athletic experience in the United States, but will also contribute to their understanding of the factors leading to an increased level of satisfaction. Providing the best possible environment to achieve high level of satisfaction ultimately will lead to a better performance on and off the field (Zhang, DeMichele \& Connaughton, 2004).
\end{abstract}

The concept of job satisfaction is one of the most studied topics in human resource management and organizational behavior, and has been an area of study since the 1950s (Cranny, Smith, \& Stone, 1992). Job satisfaction is one of the main factors determining job productivity and performance (Edwards, Bell, Arthur, \& Decuir, 2008). Evaluating job satisfaction in the realm of sport particularly is not new to academia. Scholars have looked at job satisfaction in different segments of the sport industry and different constructs have been examined in considering which variables affect job satisfaction. For example, Smucker and Kent (2004) examined job satisfaction among sport administrators in a variety of settings-professional sport, fitness and park recreation. Another area of study of job satisfac-

The authors are with the Dept. of Kinesiology, Recreation and Sport Studies, University of Tennessee, Knoxville, TN. 
tion has been collegiate athletics. For example, Robinson, Peterson, Tedrick, and Carpenter (2003) evaluated the level of job satisfaction among athletic directors in the NCAA Division III schools. They found these individuals to be mostly satisfied with their positions. The key finding was that athletic directors who did not have any other responsibilities were more satisfied with their job than those who had other responsibilities. Division III institutions generally have a small staff of administrators that manage and operate the athletic department. Therefore, it is not uncommon for an athletic director to also have coaching, teaching or other administrative responsibilities (Robinson, Peterson, Tedrick, \& Carpenter, 2003). Chelladurai and Ogasawara (2003) also evaluated job satisfaction at the collegiate level but focused on coaches. Those scholars evaluated satisfaction in the job of coaching and noted that coaches' satisfaction with facilities, media and community support, team performance and athletes' academic progress were unique to collegiate coaching.

Realizing the importance recreational programs play on college campuses, Zhang, DeMichele and Connaughton (2004) studied midlevel campus recreation program administrators who generally have very demanding jobs. They measured satisfaction in regards to organizational work environment and individual work environment. Both factors were important to midlevel campus recreation administrators but organizational work environment explained more of the variance in overall satisfaction. Organizational work environment referred to items such as organizational structure, internal communications, professional development opportunities and regards for personal concern. Individual work environment included items such as relationship with colleagues, independence, and compensation. They also found institutional size, type of institution, and years of employment to be related to job satisfaction.

A population that has received growing attention is athletic trainers. Mazerolle, Bruening, Casa and Burton (2008) examined work-family conflict among athletic trainers and how this affects burnout and intention to leave the job. Similarly focusing on athletic trainers, Brumels and Beach (2008) examined professional role complexity and its effect on job satisfaction, suggesting that collegiate athletic trainers began to experience less job satisfaction and more thoughts of leaving when moderate to high stress levels occurred due to role ambiguity, overload, incongruity, incompetence and conflict.

While it is evident that some work has been done in the area of job satisfaction in college athletics, the majority of research has been focused on administrators and professional staff, overlooking student-athletes, who, in general, are not classified as employees, but without whom athletics would not exist. Although student-athletes are not strictly speaking viewed as employees, for the purpose of this study, we will view them as employees for the following reason. As Chelladurai and Riemer (1997) point out, intercollegiate athletics are perceived as entertainment, therefore making it possible to view student-athletes as the prime producers of this entertainment. Understanding job satisfaction of professionals involved with the operations of collegiate sport is important, but understanding satisfaction of student-athletes is equally, if not even more, important considering the crucial role student-athletes play in collegiate athletics. Multiple expectations from coaches, administrators and the community are placed on student-athletes. It is, therefore, essential to understand their academic and athletic experience and more particularly their level of satisfaction 
with that experience. This can lead to better performances both athletically and academically (Zhang, DeMichele \& Connaughton, 2004).

The number of international student-athletes participating in the NCAA has nearly doubled since the turn of the century, from 8,945 in 2001-02 to 16,440 in 2007-08 (DeHass, 2009) (see Figure 1). There is no doubt about the role and importance those athletes play in collegiate sport, but the literature on international student-athletes is rather scarce. International student-athletes have been studied with the purpose of identifying the motivation of those athletes to come to the United States (Berry, 1999; Jones, Koo, Kim, Andrew, \& Hardin, 2008) or on their adjustment to college (Ridinger \& Pastore, 2000b). Therefore, there is a need for academic research focusing on and evaluating the experience (both athletic and academic) of international student-athletes in particular.

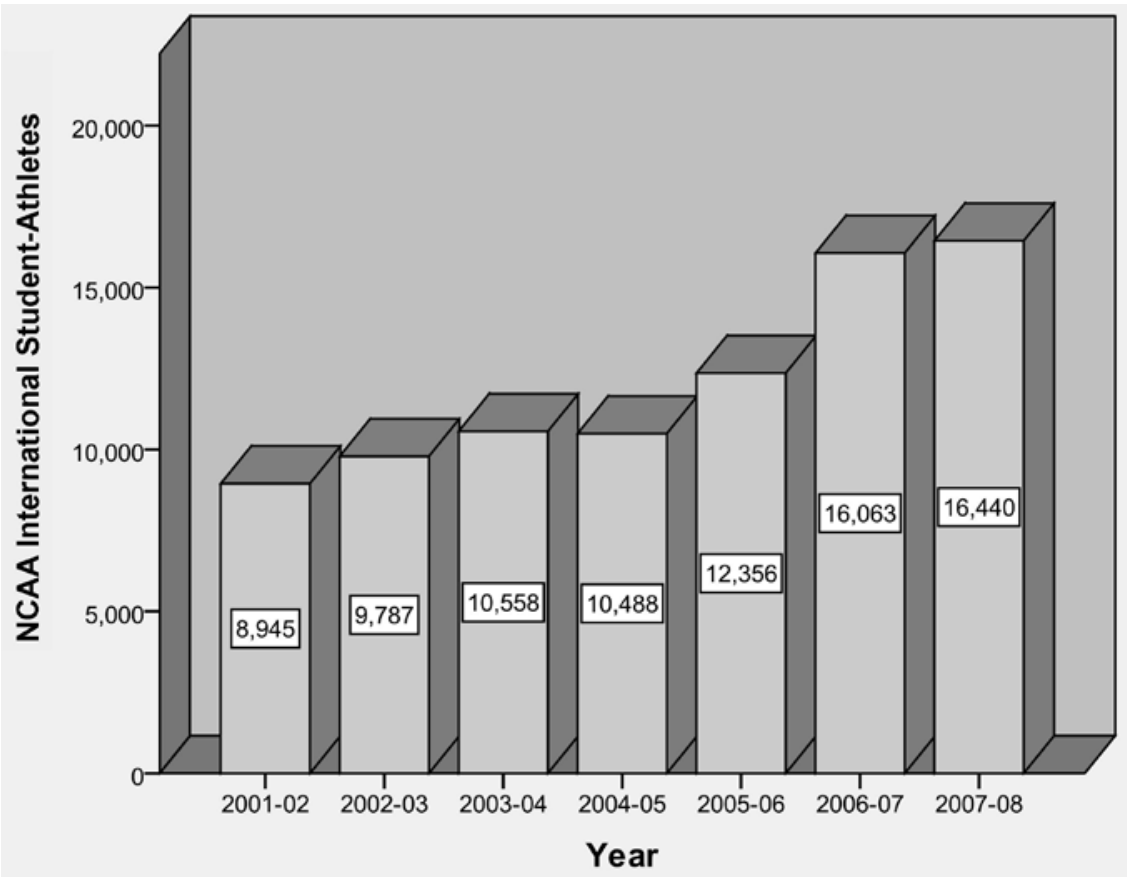

Figure 1 - Number of International Student-athletes in NCAA

\section{Review of Literature}

\section{Student Satisfaction}

Research has examined many different aspects of student satisfaction in higher education. Studies have examined overall student satisfaction and explored specific independent variables and their relationship with satisfaction. Demographic 
variables have been used as well in determining what influence they may have on the experience of a student at an institution of higher education.

Kim and Sax (2009) examined the role of student-faculty interaction in the satisfaction of the college experience. The primary purpose of this study was to examine the variables that may influence the satisfaction level of student-faculty interaction including gender, ethnicity, social class and first generation status. Outcome variables that were used included: grade point average, degree choice, cultural appreciation and satisfaction with their college experience. The two categories examined related to this study were satisfaction with advising on academic matters and satisfaction with access to faculty outside of class. The results showed that access to faculty does play a role in the overall satisfaction with the college experience. Females and nonfirst generation students had higher levels of satisfaction, and differences also existed in ethnicity and social class. The authors added that class-related student-faculty interaction improved satisfaction for all groups except African-Americans (Kim \& Sax, 2009). Hale, Graham, and Johnson (2009) explored the issue of academic advising satisfaction among undergraduates at a university in the southern United States. Developmental advising was identified as the type of advising that students preferred and higher levels of satisfaction resulted in students whose advisors used that style (Hale, Graham, \& Johnson, 2009). Developmental advising is based on the personal relationship between advisors and students and includes not only academic goals but career and personal goals as well. The alternative to development advising is prescriptive advising where the emphasis is placed on the specific issues that need to be addressed to ensure graduation (Jordan, 2000). Quality advising should enhance a student's academic experience and thus lead to higher levels of satisfaction.

Landrum and Elison-Bowers (2009) found that psychology students were generally satisfied with their decision to major in psychology, and the opportunities the degree has given to them. Satisfaction with online course instruction was examined by Yukselturk and Yildirim (2008). The findings showed the participants were generally satisfied with the program but satisfaction decreased near the end of the program. Factors influencing satisfaction were interaction with faculty and fellow students, course design, flexibility and institutional support (Yukselturk \& Yildirim, 2008). Another study investigating satisfaction with e-learning examined the Blackboard system. Liaw (2007) found that system and multimedia quality are what lead to high levels of satisfaction.

A different approach to examining student satisfaction was undertaken by Brown and Mazzarol (2008) in which they approached students as consumers. They investigated the role the image of the institution has on student satisfaction and the perceived value of the college experience. Their sample was drawn from students enrolled in Australian universities, and the findings indicated that the image of the university had a relationship with satisfaction and perceived value (Brown \& Mazzarol, 2008). International students' satisfaction with health and counseling services at universities in Australia were examined as part of a larger study by Russell, Thomson, and Rosenthal (2008). They found that although international students were satisfied with the services offered to them, they could not fully take advantage of those offerings (Russell, Thomson, \& Rosenthal, 2008). An examination of Turkish students' satisfaction of life in the United States during college was part of a larger study conducted by Kilinc and Granello (2003), and they found 
overall satisfaction fell between satisfied and highly satisfied. One aspect of the Kilinc and Granello (2003) study was measuring the respondents' perception of their adaption to American culture in terms of language, customs, and traditions.

\section{Application to International Student-Athletes}

The aforementioned studies could be applicable to international student-athletes. Kim and Sax (2009) recommended that a "one size fits all" approach should not be undertaken in regards to student-faculty interaction (p. 459). Different groups have different needs and this will play a role in the satisfaction of students with the college experience. Thus, it is important to investigate other groups within the college population. This leads to the investigation of not only student-athletes but international student-athletes in particular. Brown and Mazzarol's (2008) results revealed that a university education is a marketable product and to attract elite international-athletes it is important to know what leads to high levels of satisfaction for this particular group of students. Understanding satisfaction in different aspects of the college experience will also increase retention rates, which will lead to higher graduation rates (Daller, 1997). Satisfaction will also lead to higher rates of academic success, which may result in postseason honors for student-athletes to include postgraduate scholarships and all-academic type teams (Yukselturk \& Yildirim, 2008). Russell, Thomson and Rosenthal (2008) found that international students were satisfied with health services, but indicated that different cultural backgrounds can influence satisfaction with services; therefore it is important to understand all facets of the college experience. This argument was supported by the findings of Kilinc and Granello (2003) as well.

There is no research available that investigates satisfaction levels or what leads to a satisfying college experience for international student-athletes. Limited research has focused on student-athletes, but not on international student-athletes. For example, collegiate student-athletes' satisfaction with athletic trainers was investigated by Unruh, Unruh, Moorman, and Seshadri (2005). The overall purpose of their study was to examine if student-athletes were satisfied with their athletic trainers and the services provided. Differences in satisfaction levels based on gender, competition levels and sport were also part of the study. The results showed that both men and women in low profile sports had lower levels of satisfaction. Level of competition (Division I or Division II) did not influence levels of satisfaction (Unruh, et al., 2005). This study could be applicable in investigating the overall satisfaction of international student-athletes. Chelladurai and Riemer (1997) have developed the student-athlete satisfaction questionnaire designed for use with intercollegiate sports. However, it has not been used to investigate international student-athletes at NCAA institutions. The questionnaire consists of 15 dimensions and is based on Chelladurai and Riemer's classification of facets of athlete satisfaction. The dimensions encompass areas of satisfaction such as individual and team performance, leadership, team, organization, and the individual him or herself.

\section{Study Significance}

It costs tens of thousands of dollars to recruit and educate an international-student athlete at a Division I-FBS university. Costs are not broken down by individual 
athletes but some universities, such as the University of Tennessee, spend more than \$1 million in football recruiting alone (Davidson, 2009; Sander, 2008). When investments of this scale are involved one would logically like to have some feedback on the satisfaction of the parties involved. It is important to understand the overall satisfaction of student-athletes with their college experience. Coaches are always looking for a student-athlete that will be a difference-maker for their team. Low levels of satisfaction of international student-athletes may discourage those athletes from attending universities in the United States and participating in collegiate sports.

Research has been conducted on satisfaction levels for different services at universities and different academic issues, but student-athletes are one subgroup that has been overlooked. Several studies have investigated international studentathlete motivation but have not examined what the perception of the experience of studying and competing in the United States has been (Bale, 1991; Berry, 1999; Garant-Jones, Koo, Kim, Andrew, \& Hardin, 2009; Ridinger \& Pastore, 2000a; Ridinger \& Pastore, 2000a, Ridinger \& Pastore, 2001; Stidwell, 1984). Garant-Jones, Koo, Kim, Andrew, and Hardin (2009) recognized this and recommended future studies should examine international student-athletes' satisfaction after experiencing intercollegiate athletics. Therefore, to fill this gap, the purpose of this study is to explore the level of satisfaction among international studentathletes participating in the NCAA Division I-FBS. In the current study, the demographic variables of gender, region of the world, type of scholarship, and type of sport were included as independent variables since previous international student-athlete studies (Berry, 1999; Garant-Jones et al., 2009) have examined differences of international student-athletes' motives to come to U.S. based on those demographic variables.

\section{Research Questions}

Two research questions emerged for this study.

1. What is the level of satisfaction of international student-athletes participating in the NCAA?

2. Does the level of satisfaction differ based on selected demographic variables?

\section{Method}

\section{Participants}

An international student-athlete was defined as a student-athlete whose country of origin was any country outside the United States. The sample for this study consisted of international student-athletes at institutions from six NCAA Division I-FBS conferences: SEC (Southeastern Conference), Pac-10 (Pacific-10 Conference), Big-12 (Big-12 Conference), Big East Conference, ACC (Atlantic Coast Conference), and Big-10 (Big-10 Conference). International student-athletes were identified through the rosters of the athletic teams of the institutions chosen for this study. E-mail addresses for 811 international student-athletes from the six conferences were collected through their universities' Web sites. 


\section{Instrument}

The questionnaire used for this study consisted of two parts. The first part included five demographic questions: (a) gender; (b) age; (c) country of origin; (d) scholarship type; and (e) sport in which the student-athlete was participating. The second part adopted Riemer and Chelladurai's (1998) Athlete Satisfaction Questionnaire (ASQ). The ASQ contains 56 items that are evaluated on a seven point Likert-type scale anchored by " $1=$ not at all satisfied" and " $7=$ extremely satisfied". The 56 items addressed aspects of athletic participation such as performance (both team and individual), leadership, the team, the organization and the individual. All items were grouped into 15 dimensions: individual performance, team performance, ability utilization, strategy, personal treatment, training and instruction, team task contribution, team social contribution, ethics, team integration, personal dedication, budget, medical personnel, academic support services and external agents. Individual performance focuses on satisfaction related to the degree to which performance goals are reached during the season and the improvement in skill level. Team performance focuses on the team's overall performance and the team's goal achievement for the season. The ability utilization dimension focuses on the coach's ability to use and maximize the individual athlete's talent and abilities. Strategy relates to the satisfaction with the strategic and tactical decisions. Personal treatment focuses on satisfaction related to the coach's behaviors that directly affect the individual, but indirectly affect the team development. The training and instruction dimension is associated with the training and instructions provided by the coach. Team task contribution focuses on satisfaction with those actions by which the team serves as a substitute for leadership for the athlete. Team social contribution on the other hand, focuses on how teammates contribute to the athlete as a person. The ethics dimension of satisfaction revolves around fair play and sportsperson like behaviors. Team integration relates to the satisfaction with the athletes' contributions and coordination of their efforts toward the team's task. Personal dedication focuses on the individual athlete's satisfaction with his/her own contribution to the team. The budget dimension of satisfaction relates to the level of satisfaction with the financial support provided to the team by the athletic department. The medical personnel dimension focuses on the medical personnel's interest in the athletes and the fairness with which the medical personnel treats all players. Academic support services relates to the satisfaction with tutoring, the academic service provided and the personnel of the academic support services. Lastly, the external agent's dimension of satisfaction relates to the support received from media, the university community as well as the local community, and the fans. In terms of reliability, the reported Cronbach's alphas of the dimensions in the ASQ ranged from 0.78 to 0.95 for Riemer and Chelladurai's (1998) study.

\section{Data Collection}

A message and the link to the on-line questionnaire were sent via electronic mail to all international student-athletes identified for the purpose of this study. E-mail reminders were sent twice, seven days apart, to the selected subjects. There were 206 valid responses to the questionnaire used for the data analysis. Therefore, the overall response rate was $25 \%$. 


\section{Data Analysis}

Procedures from the SPSS 17.0 software were used for the data analysis. Descriptive statistics were calculated to assess overall demographic information of participants. Cronbach internal consistency analysis was conducted to evaluate interitem reliability of each dimension of student-athlete satisfaction. Mann-Whitney $U$ and Kruskal-Wallis tests, the nonparametric equivalents of the independent $t$ test and one way analysis of variance, were adopted as a conservative option of analysis to explore the level of job satisfaction of international student-athletes in terms of gender (male vs. female), region of the world (South or North America, Africa, Asia, Australia, and Europe), type of scholarship (full, partial, and none), and type of sport (individual vs. team). Some of the groups based on the classification of international student-athletes only had a small number of observations and there were unequal sizes within certain groups to employ parametric statistics. Therefore, nonparametric statistics was used to examine the differences in average rank among the observed distributions since it was not necessary to assume that the observations are normally distributed and did not require a large sample (Siegel \& Castellan, 1988). Other studies (Garant-Jones et al., 2009; Kim, Andrew, Mahony, \& Hums, 2008) have also used nonparametric statistics to assess differences of groups based on those demographic variables due to unequal cell sizes within certain groups or small number of observations for certain groups. With regard to type of sport, NCAA's classification was used to categorize the variety of sports as individual sports or team sports (NCAA Academic and Membership Affairs Staff, 2009).

\section{Results}

\section{Demographics of International Student-Athletes}

The mean age of the participants was $20.69(S D=1.52)$ ranging from 18 to 25 . Among the 206 respondents, the majority of the international student-athletes were female $(n=146 ; 70.9 \%)$ and received full athletic scholarships $(n=149 ; 72.3 \%)$ during their participation in intercollegiate athletics in the United States. One hundred thirty-three respondents participated in individual sports, such as fencing, golf, gymnastics, track and field, skiing, swimming, synchronized swimming and tennis. Seventy-three respondents participated in team sports, such as basketball, field hockey, football, lacrosse, rowing, soccer, volleyball, and water polo. The five sports with the largest number of participants were tennis $(n=39 ; 18.9 \%)$, swimming and diving $(n=36 ; 17.5 \%)$, rowing $(n=33 ; 16.0 \%)$, track and field $(n=29$; $14.1 \%)$, and golf $(n=19 ; 9.2 \%)$. Table 1 provides more information regarding the 206 international student-athletes who participated in the study.

\section{Scale Reliabilities}

Internal consistency was examined for each of the 15 dimensions of athlete satisfaction. Cronbach alpha's for each dimension are also shown in Table 2. Initial reliabilities for each category for the instrument ranged from .776 for personal dedication to .950 for strategy. Scale reliabilities exceeded the recommended .700 benchmark and were shown to have an acceptable level of reliability (Nunnally \& Bernstein, 1994). 
Table 1 Demographics of International Student-Athletes

\begin{tabular}{llcc}
\hline & & N & $\%$ \\
\hline Gender & Male & 60 & 29.1 \\
& Female & 146 & 70.9 \\
\hline Scholarship & Full-scholarship & 149 & 72.3 \\
& Partial-scholarship & 43 & 20.9 \\
& No-scholarship & 14 & 6.8 \\
\hline Top Five Sports & Tennis & 39 & 18.9 \\
& Swimming \& diving & 36 & 17.5 \\
& Rowing & 33 & 16.0 \\
& Track \& field & 29 & 14.1 \\
& Golf & 19 & 9.2 \\
\hline Continent & Europe & 88 & 42.7 \\
& America & 64 & 31.1 \\
& Oceania & 21 & 10.2 \\
& Asia & 17 & 8.3 \\
& Africa & 16 & 7.8 \\
\hline Conference & Big 10 & 51 & 24.8 \\
& ACC & 47 & 22.8 \\
& Pac 10 & 47 & 22.8 \\
& Big 12 & 30 & 14.6 \\
& Big East & 19 & 9.2 \\
& SEC & 12 & 5.8 \\
\hline
\end{tabular}

\section{Means and Standard Deviations of Athlete Satisfaction}

Table 2 shows the means and standard deviations for the 15 dimensions of athlete satisfaction in terms of gender, region of the world, type of scholarship received, and type of sport. The range of the possible score for each dimension was zero to seven. For the current study, the midpoint of the scale (4.00) was interpreted as neutral attitudes toward each dimension (indicating neither satisfaction nor dissatisfaction), and above the midpoint indicated satisfaction (Parks \& Para, 1994). For the entire sample, the means for the 15 dimensions of athlete satisfaction ranged from 4.95 (individual performance) to 5.97 (academic support service). According to these data, all of the means for each dimension were above 4.00, which indicated that international student-athletes were satisfied with all of the dimensions in this study. Of the 15 dimensions, academic support service was the most highly ranked, followed by personal dedication (5.91), team/group social contribution (5.83), and ethics (5.77).

\section{Effects of Demographics on Athlete Satisfaction}

The current study examined the level of satisfaction of international student-athlete in terms of gender (male vs. female), region of the world (South or North America, Africa, Asia, Australia, and Europe), type of scholarship (full, partial, and none), 


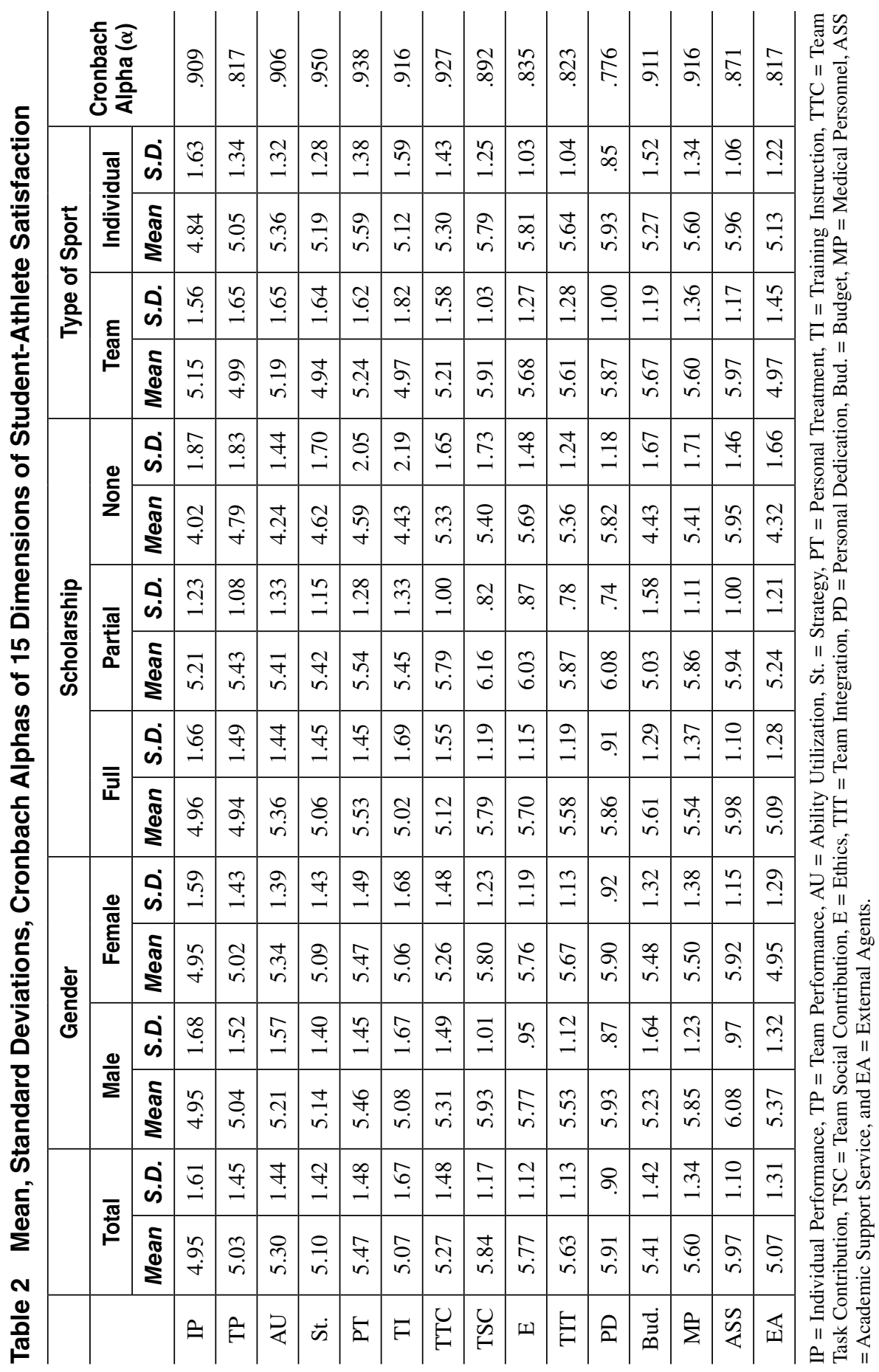


and type of sport (individual vs. team). The results of the Mann-Whitney $U$ test and Kruskal-Wallis test indicated that the equalities of the average rank over gender and type of scholarship were statistically significant, while the ranks for region and type of sport were not significant.

Differences in Satisfaction Based on Gender. The average ranks for the 15 dimensions of athlete satisfaction are listed separately for both groups in Table 3. Since a ranking of 1 is assigned to the smallest value, the average ranks were smaller for male athletes for ability utilization, personal training, ethics, team integration, and budget. The results of the Mann-Whitney Test showed main effect of gender on external agents $[U=3483.50, p=.021]$, while those on the

\section{Table 3 Differences in Athlete-Satisfaction based on Gender}

\begin{tabular}{|c|c|c|c|c|c|}
\hline Satisfaction & Gender & $\mathbf{N}$ & Mean Rank & Mann-Whitney-U & $p$ \\
\hline \multirow[t]{2}{*}{ Individual Performance } & Male & 60 & 104.11 & 4343.50 & .925 \\
\hline & Female & 146 & 103.25 & & \\
\hline \multirow[t]{2}{*}{ Team Performance } & Male & 60 & 105.62 & 4253.00 & .743 \\
\hline & Female & 146 & 102.63 & & \\
\hline \multirow[t]{2}{*}{ Ability Utilization } & Male & 60 & 102.50 & 4320.00 & .877 \\
\hline & Female & 146 & 103.91 & & \\
\hline \multirow[t]{2}{*}{ Strategy } & Male & 60 & 103.96 & 4352.50 & .944 \\
\hline & Female & 146 & 103.31 & & \\
\hline \multirow[t]{2}{*}{ Personal Treatment } & Male & 60 & 103.45 & 4377.00 & .994 \\
\hline & Female & 146 & 103.52 & & \\
\hline \multirow[t]{2}{*}{ Training Instruction } & Male & 60 & 103.97 & 4352.00 & .942 \\
\hline & Female & 146 & 103.31 & & \\
\hline \multirow[t]{2}{*}{ Team Task Contribution } & Male & 60 & 105.33 & 4270.00 & .776 \\
\hline & Female & 146 & 102.75 & & \\
\hline \multirow[t]{2}{*}{ Team Social Contribution } & Male & 60 & 106.78 & 4183.00 & .609 \\
\hline & Female & 146 & 102.15 & & \\
\hline \multirow[t]{2}{*}{ Ethics } & Male & 60 & 99.83 & 4160.00 & .567 \\
\hline & Female & 146 & 105.01 & & \\
\hline \multirow[t]{2}{*}{ Team Integration } & Male & 60 & 97.03 & 3992.00 & .316 \\
\hline & Female & 146 & 106.16 & & \\
\hline \multirow[t]{2}{*}{ Personal Dedication } & Male & 60 & 104.37 & 4328.00 & .893 \\
\hline & Female & 146 & 103.14 & & \\
\hline \multirow[t]{2}{*}{ Budget } & Male & 60 & 99.34 & 4130.50 & .519 \\
\hline & Female & 146 & 105.21 & & \\
\hline \multirow[t]{2}{*}{ Medical Personnel } & Male & 60 & 115.33 & 3670.00 & .066 \\
\hline & Female & 146 & 98.64 & & \\
\hline \multirow[t]{2}{*}{ Academic Support Service } & Male & 60 & 108.34 & 4089.50 & .448 \\
\hline & Female & 146 & 101.51 & & \\
\hline \multirow[t]{2}{*}{ External Agents } & Male & 60 & 118.44 & $3483.50 * *$ & .021 \\
\hline & Female & 146 & 97.36 & & \\
\hline
\end{tabular}

Notes. ${ }^{*} p<.05, * * p<.01$ 
other 14 dimensions were not statistically significant at the .05 level. Thus, male international student-athletes had been significantly more satisfied with external agents than female international student-athletes.

Differences in Type of Scholarship. The average ranks for ability utilization and budget of athlete satisfaction are separately shown in Table 4 in terms of type of scholarship (full, partial, and none). Based on the descriptive statistics, the average ranks were higher for fully funded student-athletes on ability utilization, personal training, and budget, while the average ranks were higher for partially funded student-athletes on most of the dimensions, except academic support service. Results of the Kruskal-Wallis test indicated that the main effects of scholarship status on two of the 15 satisfaction dimensions were significant at the .05 level (ability utilization $\left[\chi^{2}(2,206)=8.156, p=.017\right]$ and budget $\left[\chi^{2}(2,206)=10.660, p\right.$ $=.005]$ ). The main effects of the rest of dimensions were not statistically significant. Therefore, a further analysis of Mann-Whitney $U$ test for ability utilization and budget was conducted. The results from the Kruskal-Wallis test found that there were differences between (a) full and none [ $U=569.50, p=.005]$ and (b) partial and none $[U=161.00, p=.009]$ in ability utilization, while there was no significant difference between full and partial [ $U=3194.00, p=.976]$. In terms of budget, the results indicated significant differences between (a) full and partial $[U=2515.00$, $p=.031]$, and (b) full and none $[U=585.00, p=.006]$, but no difference between partial and none $[U=235.00, p=.219]$. As a result, international student-athletes who are fully funded in their sport participation are generally more satisfied with ability utilization and budget than those who have partial or no financial support by their institutions.

\section{Discussion and Conclusion}

The findings of this study indicate that international student-athletes are satisfied with their overall academic and athletic experience at NCAA Division I-FBS institutions. Mean scores for each of the 15 dimensions of satisfaction were above 5.0, except for individual performance. Providing a college experience that leads to a high level of satisfaction is important since dissatisfaction among students could ultimately lead to drop out and attrition. Further, "satisfied students are necessary to accomplish the goals of higher education institutions" (Kara \& DeShields, 2004, p.12). This statement is also supported by human resource management research, which has indicated that satisfied employees are more likely to continue to commit to the organization, set higher performance goals, maintain at better performance level, accept more responsibilities, and take leadership roles (Zhang, DeMichele, \& Connaughton, 2004).

Findings revealed high levels of satisfaction in team social contribution (5.84) and team integration (5.63). Team integration (also referred to in the literature as "team cohesion") is important for the success of the team (Carron \& Chelladurai, 1981; Carron, Colman, Wheeler, \& Stevens, 2002). It is challenging for coaches and athletic staff to provide the right conditions for team cohesion. Each year some student-athletes graduate and leave, while new ones join the team, therefore frequently changing the make-up of the team. Research has examined the relationship between cohesion and coaching and pointed out some of the possible 
Table 4 Differences in Athlete-Satisfaction based on Type of Scholarship

\begin{tabular}{|c|c|c|c|c|c|}
\hline & Scholarship & $\mathbf{N}$ & Mean Rank & $\chi^{2}$ & $p$ \\
\hline \multirow[t]{3}{*}{ Individual Performance } & Full & 149 & 105.27 & 4.616 & .099 \\
\hline & Partial & 43 & 108.01 & & \\
\hline & None & 14 & 70.82 & & \\
\hline \multirow[t]{3}{*}{ Team Performance } & Full & 149 & 99.49 & 3.592 & .166 \\
\hline & Partial & 43 & 118.77 & & \\
\hline & None & 14 & 99.32 & & \\
\hline \multirow[t]{3}{*}{ Ability Utilization } & Full & 149 & 106.74 & $8.156^{*}$ & .017 \\
\hline & Partial & 43 & 106.53 & & \\
\hline & None & 14 & 59.68 & & \\
\hline \multirow[t]{3}{*}{ Strategy } & Full & 149 & 102.14 & 2.708 & .258 \\
\hline & Partial & 43 & 114.07 & & \\
\hline & None & 14 & 85.54 & & \\
\hline \multirow[t]{3}{*}{ Personal Training } & Full & 149 & 105.96 & 3.242 & .198 \\
\hline & Partial & 43 & 103.92 & & \\
\hline & None & 14 & 76.07 & & \\
\hline \multirow[t]{3}{*}{ Training Instruction } & Full & 149 & 101.80 & 2.211 & .331 \\
\hline & Partial & 43 & 113.88 & & \\
\hline & None & 14 & 89.68 & & \\
\hline \multirow[t]{3}{*}{ Team Task Contribution } & Full & 149 & 97.56 & 5.976 & .050 \\
\hline & Partial & 43 & 122.36 & & \\
\hline & None & 14 & 108.79 & & \\
\hline \multirow[t]{3}{*}{ Team Social Contribution } & Full & 149 & 100.33 & 3.554 & .169 \\
\hline & Partial & 43 & 118.10 & & \\
\hline & None & 14 & 92.43 & & \\
\hline \multirow[t]{3}{*}{ Ethics } & Full & 149 & 99.76 & 2.324 & .313 \\
\hline & Partial & 43 & 115.06 & & \\
\hline & None & 14 & 107.79 & & \\
\hline \multirow[t]{3}{*}{ Team Integration } & Full & 149 & 102.51 & 1.898 & .387 \\
\hline & Partial & 43 & 112.02 & & \\
\hline & None & 14 & 87.89 & & \\
\hline \multirow[t]{3}{*}{ Personal Dedication } & Full & 149 & 100.21 & 1.976 & .372 \\
\hline & Partial & 43 & 114.63 & & \\
\hline & None & 14 & 104.29 & & \\
\hline \multirow[t]{3}{*}{ Budget } & Full & 149 & 111.19 & $10.660 * *$ & .005 \\
\hline & Partial & 43 & 89.02 & & \\
\hline & None & 14 & 66.07 & & \\
\hline \multirow[t]{3}{*}{ Medical Personnel } & Full & 149 & 100.97 & 1.400 & .497 \\
\hline & Partial & 43 & 113.00 & & \\
\hline & None & 14 & 101.29 & & \\
\hline \multirow[t]{3}{*}{ Academic Support Service } & Full & 149 & 104.35 & .474 & .789 \\
\hline & Partial & 43 & 98.60 & & \\
\hline & None & 14 & 109.46 & & \\
\hline \multirow[t]{3}{*}{ External Agents } & Full & 149 & 103.95 & 3.321 & .190 \\
\hline & Partial & 43 & 110.48 & & \\
\hline & None & 14 & 77.29 & & \\
\hline
\end{tabular}


predictors of team cohesion such as class standing, team record, funding, travel accommodation, coaching staff and academic policy (Aghazadeh \& Kyei, 2009). In fact, scholars have developed an instrument to measure coaching staff cohesion that could be used in the assessment of cohesion among coaches (Martin, 2002). This is important since coaching staff cohesion contributes to the cohesion of the team as a whole (Blackburn, 1985) and consequently could lead to team success (Carron, Colman, Wheeler, \& Stevens, 2002).

Related to the above discussion about athletes' satisfaction with team integration is the issue of personal treatment of athletes. Our findings also indicated a high level of satisfaction with this particular dimension (5.47). The way coaches treat athletes affects their performance on the field and their psychological well-being (Wang, Callahan, \& Goldfine, 2001). This is particularly challenging considering that international student-athletes possess a variety of cultural differences that coaches and athletic staff need to take into account. Therefore, to continue to provide a high-level of satisfaction in regards to personal treatment of international studentathletes, coaches need to consider cultural differences to ensure an environment that is most favorable to athletes' learning and performance.

Regardless of gender, scholarship type or sport played, international studentathletes were satisfied with their collegiate experience. Our results indicate that differences occur with gender for the satisfaction dimension associated with external agents. External agents are agents or elements outside the organization that may contribute to the team's satisfaction such as media support, community support and fans. Males had a higher rate of satisfaction in this area than females. This could be explained partially by the fact that male athletes receive more media exposure than female athletes do (Eagleman, Pedersen, \& Wharton, 2009). In fact, previous research supports this argument and points out that in higher education institutions college newspapers cover male athletes and events in $72.7 \%$ of their sports stories, and college television operations devote $81.5 \%$ of their sports stories to males (Huffman, Tuggle, \& Rosengard, 2004). Therefore, efforts should be made to provide more media exposure of female athletes and encourage the development of a closer relationship with fans and the community.

Satisfaction levels were also different with regards to budget. This is not surprising as it appears logical that student-athletes receiving full or partial scholarships would be more satisfied than those not receiving financial assistance. Previous work argues that athletic scholarship affects athletes' motivation to participate in sport (Medic, Mack, Wilson, \& Starkes, 2007). Therefore, coaches and athletic administration may need to consider additional incentives for those international student-athletes who are not receiving any financial support.

The results of this research have some practical implications. First, there are practical benefits to coaches and athletic staff. Some of the dimensions of satisfaction measured coach's training style. Knowing whether student-athletes were satisfied or not with these dimensions could assist coaches and athletic staff in modifying training strategies and leadership styles. This in turn has the potential to enhance the student-athletes' experience and the effectiveness of the athletic department. In fact, Chelladurai and Riemer (1997) noted that "athlete satisfaction may indeed prove to be the ultimate measure of organizational effectiveness of an athletic program" (p. 135).

Another area with practical implications is the experience international studentathletes had with academic services. The work of Hale et al., (2009), who evaluated 
academic advising experience of students, concluded that satisfaction with academic advising enhanced the academic experience and led to higher levels of satisfaction. Our findings indicate that the highest dimension of satisfaction among international student-athletes was in the area of academic support services. Knowing this is important because if universities and colleges continue providing a high quality of academic services, such efforts would continue to contribute to the overall academic satisfaction of international student-athletes. This is important for student-athletes in that they know they will receive a quality academic experience as well as an athletic experience, both of which influence the overall college experience.

Recruiting is a vital component of any university or college athletic department's efforts to attract the best athletic potential. In fact, as Letawsky and colleagues pointed out "recruiting top student-athletes is even more strategic due to the potential increase in undergraduate admissions and booster donations that a championship season may bring." (Letawsky, Schneider, Pedersen, \& Palmer, 2003, p. 1). Coaches seek to recruit the most athletically talented players to provide the university with a winning record. Therefore, knowing what the dimensions of satisfaction among international student-athletes are could contribute to the modification of existing recruiting strategies for international athletes and assist in the effort to bring in the best athletes.

This study contributes to the existing body of literature on students in general and student-athletes in particular in that it takes the existing research a step further and looks at the experiences of a unique population of students (international student-athletes) by exploring their level of satisfaction. More specifically, this study evaluated the overall academic and athletic experience of international studentathletes and did not focus on specific aspects of satisfaction of student-athletes (e.g., satisfaction with athletic trainers), which resulted in a broader description of their overall experience.

This research only focused on international student-athletes in NCAA Division I-FBS schools and is therefore, not representative of the entire international student-athlete population. Further studies are needed to examine Division I-FCS, Division II and III institutions and make comparisons across the various levels of intercollegiate athletics. Future research should also compare international studentathletes' level of satisfaction with that of U.S. student-athletes.

Another area of interest would be to look at the relationship between satisfaction and level of commitment among athletes, both domestic and international. Levels of commitment could determine the desire or lack of desire to transfer to another college or even leave to join a professional sport team. Satisfaction and commitment are interrelated and important concepts to study in the area of organizational behavior and human resource management (William \& Hazer, 1986).

Last, but not least, it would be beneficial to explore the effect of satisfaction on performance. In fact, previous research has indicated that job satisfaction can be a good predictor of performance (Cotton \& Tuttle, 1986). While important to understand this correlation and provide the conditions necessary to improve academic and athletic performance, we need to be aware of the variables affecting performance that are out of the control of athletes and administrators, such as unexpected injuries and other unplanned events. 


\section{References}

Aghazadeh, S.M., \& Kyei, K. (2009). A quantitative assessment of factors affecting college sports' team unity. College Student Journal, 43(2), 294-302.

Bale, J. (1991). The Brawn Drain: Foreign Student-Athletes in American Universities. Urbana (Caracas, Venezuela), XXX, IL University of Illinois.

Blackburn, J. (1985). Systematic program for the development of staff cohesion. In L.K. Bunker, R.J. Rotella, \& A.S. Reilly (Eds.), Sport psychology: Psychological considerations for maximizing sport performance (pp. 93-100). Ann Arbor, MI: McNaughton \& Gunn.

Berry, J.R. (1999). Foreign student-athletes and their motives for attending North Carolina NCAA Division I institutions: Unpublished master's thesis. University of North Carolina at Chapel Hill.

Brown, R., \& Mazzarol, T. (2008). The importance of institutional image to student satisfaction and loyalty within higher education. Higher Education, 58, 81-95.

Brumels, K., \& Beach, A. (2008). Professional role complexity and job satisfaction of collegiate certified athletic trainers. Journal of Athletic Training, 43(4), 373-378.

Carron, A.V., \& Chelladurai, P. (1981). The dynamics of group cohesion in sport. Journal of Sport Psychology, 3, 123-139.

Carron, A.V., Colman, M.M., Wheeler, J., \& Stevens, D. (2002). Cohesion and performance in sport: A meta analysis. Journal of Sport \& Exercise Psychology, 24, 168-187.

Chelladurai, P., \& Ogasawara, E. (2003). Satisfaction and commitment of American and Japanese collegiate coaches. Journal of Sport Management, 17, 62-73.

Chelladurai, P., \& Riemer, H.A. (1997). A classification of the facets of athlete satisfaction. Journal of Sport Management, 11, 133-159.

Cotton, J.L., \& Tuttle, J.M. (1986). Employee turnover: A meta-analysis and review with implications for research. Academy of Management Review, 11(1), 55-70.

Cranny, C.J., Smith, P.C., \& Stone, E.F. (1992). Job satisfaction: How people feel about their jobs and how it affects their performance. New York: Macmillan.

Dailer, M.L. (1997). The use of developmental advising models by professional academic advisors. Unpublished master's thesis, Virginia Polytechnic Institute and State University, Blacksburg, VA.

Davidson, J. (2009). Inside the recruiting budget numbers. Retrieved December 14, 2009 from http://www.ncsasports.org/blog/2009/07/23/inside-the-recruiting-budget-numbers/.

DeHass, D. (2009). 2007-08 NCAA Student-Athlete Race/Ethnicity Report. Indianapolis, IN: The National Collegiate Athletic Association.

Eagleman, A.N., Pedersen, P.M., \& Wharton, R. (2009). The coverage of gender in ESPN The Magazine: An examination of articles and photographs. International Journal of Sport Management, 10(2), 226-242.

Edwards, B.D., Bell, S.T., Arthur, W., \& Decuir, A.D. (2008). Relationships between facets of job satisfaction and task and contextual performance. Applied Psychology: An International Review, 57(3), 441-465.

Garant-Jones, S., Koo, G., Kim, S., Andrew, D., \& Hardin, R. (2009). Motivations of International Student-Athletes to Participate in Intercollegiate Athletics. Journal of Contemporary Athletics, 3(4), 295-314.

Hale, M., Graham, D., \& Johnson, D. (2009). Are students more satisfied with academic advising when there is congruence between current and preferred advising styles? College Student Journal, 43(2), 313-324.

Huffman, S., Tuggle, C.A., \& Rosengard, D.S. (2004). How campus media cover sports: The gender-equity issue, one generation later. Mass Communication \& Society, 7(4), 475-489.

Jones, S.G., Koo, G.Y., Kim, S., Andrew, D., \& Hardin, R. (2008). Motivations of international student-athletes to participate in intercollegiate athletics. Journal of Contemporary Athletics, 3(4), 295-314. 
Jordan, P. (2000). Advising college students in the 21st century. NACDA Journal, 20(2), 126-136.

Kara, A., \& DeShields, O.W. (2004). Business Student Satisfaction, Intentions and Retention in Higher Education: An Empirical Investigation. Marketing Educator Quarterly, $3(1), 1-25$.

Kim, S., Andrew, D.P.S., Mahony, D.F., \& Hums, M.A. (2008). Distributive justice in intercollegiate athletics: Perceptions of student athletes. International Journal of Sport Management, 9, 379-393.

Kim, Y., \& Sax, L. (2009). Student-faculty interaction in research universities: Differences by student gender, race, social class, and first-generation status. Research in Higher Education, 50, 437-459.

Kilinc, A., \& Granello, P. (2003). Overall life satisfaction and help-seeking attitudes of Turkish college students in the United States: Implications for college counselors. Journal of College Counseling, 6, 56-68.

Landrum, R.E., \& Elison-Bowers, P. (2009). The post-baccalaureate perceptions of psychology alumni. College Student Journal, 43(2), 676-681.

Letawsky, N., Schneider, R.J., Pedersen, P.M., \& Palmer, K.J. (2003). Factors influencing the college selection process of student-athletes: Are their factors similar to non-athletes? College Student Journal, 37(4), 604-610.

Liaw, S. (2007). Investigating student's perceived satisfaction, behavioral intention, and effectiveness of e-learning: A case study of the Blackboard system. Computers \& Education, 51, 864-873.

Martin, K.A. (2002). Development and validation of the coaching staff cohesion scale. Measurement in Physical Education and Exercise Science, 6(1), 23-42.

Mazerolle, S.M., Bruening, J.E., Casa, D.J., \& Burton, L.J. (2008). Work-Family conflict, Part II: Job and life satisfaction in National Collegiate Athletic Association Division I-A certified athletic trainers. Journal of Athletic Training, 43(5), 513-522.

Medic, N., Mack, D.E., Wilson, P.M., \& Starkes, J.L. (2007). The effects of athletic scholarship on motivation in sport. Journal of Sport Behavior, 30(3), 292-306.

NCAA Academic and Membership Affairs Staff. (2009). 2009-10 NCAA Division I Manual. Indianapolis, IN: National Collegiate Athletic Association.

Nunnally, J.C., \& Bernstein, I.H. (1994). Psychometric theory. New York: McGraw-Hill.

Parks, J.B., \& Para, L.F. (1994). Job Satisfaction of Sport Management of Alumnae/i. Journal of Sport Management, 8, 49-56.

Ridinger, L.L., \& Pastore, D.L. (2000a). International student-athletes adjustment to college: A preliminary analysis. NACADA Journal, 20(1), 33-41.

Ridinger, L.L., \& Pastore, D.L. (2000b). A proposed framework to identify factors associated with international student-athlete adjustment to college. International Journal of Sport Management, 1, 4-24.

Ridinger, L.L., \& Pastore, D.L. (2001). Coaches Perceptions of Recruiting International Student-Athletes. Journal of the International Council for Health, Physical Education, Recreation, Sport, and Dance, 37(1), 18-25.

Riemer, H.A., \& Chelladurai, P. (1998). Development of the Athlete Satisfaction Questionnaire (ASQ). Journal of Sport \& Exercise Psychology, 20, 127-156.

Robinson, M. J., Peterson, M., Tedrick, T., \& Carpenter, J. R. (2003). Job satisfaction on NCAA Division III athletic directors: Impact of job design and time on task. International Sports Journal, Summer, 46-57.

Russell, J., Thomson, G., \& Rosenthal, D. (2008). International student use of university health and counseling services. Higher Education, 56, 59-75.

Sander, L. (2008). Have money, will travel: The quest for top athletes. The Chronicle of Higher Education, 54(47), A1-A11.

Siegel, S., \& Castellan, N.J. (1988). Nonparametric Statistics for the Behavioral Sciences, McGraw-Hill. 
Smucker, M. K., \& Kent, A. (2004). The influence of referent selection on pay, promotion, supervision, work, and co-worker satisfaction across three distinct sport industry segments. International Sports Journal, Winter, 27-43.

Stidwell, H.F. (1984). Motives towards track and field competition of foreign and domestic grant-in-aid student-athletes in NCAA Division 1 colleges and universities. Unpublished doctoral dissertation. Oregon State University.

Unruh, S., Unruh, N., Moorman, M., \& Seshadri, S. (2005). College student-athletes' satisfaction with athletic trainers. Journal of Athletic Training, 40(1), 52-55.

Wang, J., Callahan, D., \& Goldfine, B. (2001). Coaches' challenges' working with substitute players at collegiate team sports. Journal of Applied Research in Coaching and Athletics, 16, 110-124.

Williams, L.J., \& Hazer, J.T. (1986). Antecedents and consequences of satisfaction and commitment in turnover models: A reanalysis using latent structural equation methods. The Journal of Applied Psychology, 71(2), 219-231.

Zhang, J.J., DeMichele, D.J., \& Connaughton, D.P. (2004). Job satisfaction among midlevel collegiate campus recreation program administrators. Journal of Sport Behavior, 27(2), 184-212.

Yukselturk, E., \& Yildirim, Z. (2008). Investigation of interaction, online support, course structure and flexibility as the contributing factors to students' satisfaction in an online certificate program. Journal of Educational Technology \& Society, 11(4), 51-65. 